\title{
Incorporation of carotenoids from paprika oleoresin into human chylomicrons
}

\author{
Antonio Pérez-Gálvez ${ }^{1}$, Hans D. Martin ${ }^{2}$, Helmut Sies ${ }^{1}$ and Wilhelm Stahl ${ }^{1 *}$ \\ ${ }^{1}$ Institute for Physiological Chemistry I and \\ ${ }^{2}$ Institute for Organic Chemistry I, Heinrich-Heine-University Düsseldorf, Düsseldorf, Germany
}

(Received 24 July 2002 - Revised 20 December 2002 - Accepted 18 January 2003)

\begin{abstract}
The intake of a carotenoid-rich diet is epidemiologically related to a lower risk for different chronic disorders like cardiovascular disease, some types of cancer or age-related macular degeneration. Red pepper (Capsicum annuum L.) and its dietary products contain a variety of carotenoids, which may contribute to the carotenoid pattern of human blood and tissues. The objective of the present study was to assess the availability of carotenoids from paprika oleoresin, including zeaxanthin, $\beta$-cryptoxanthin, $\beta$-carotene and the paprika-specific oxocarotenoids capsanthin and capsorubin. After overnight fasting, the volunteers $(n 9)$ ingested a single dose of the paprika oleoresin containing $6.4 \mathrm{mg}$ zeaxanthin, $4.2 \mathrm{mg} \beta$-cryptoxanthin, $6.2 \mathrm{mg} \beta$-carotene, $35.0 \mathrm{mg}$ capsanthin and $2.0 \mathrm{mg}$ capsorubin. At different time points the carotenoid pattern in the chylomicron fraction was analysed to evaluate carotenoid absorption. From the major carotenoids present in the paprika oleoresin only zeaxanthin, $\beta$-cryptoxanthin and $\beta$-carotene were detectable in considerable amounts. Although the xanthophylls in paprika oleoresin were mainly present as mono- or di-esters, only free zeaxanthin and $\beta$-cryptoxanthin were found in human samples. The bioavailability of the pepper-specific carotenoids capsanthin and capsorubin from paprika oleoresin is very low. However, oleoresin is a suitable source for the provitamin A carotenoids $\beta$-carotene and $\beta$-cryptoxanthin and the macular pigment zeaxanthin.
\end{abstract}

Bioavailability: Paprika carotenoids: Xanthophyll esters

Paprika oleoresin is a product derived from red pepper (Capsicum annuum L.) (Mínguez-Mosquera \& Pérez-Gálvez, 1998a). It is an oil with high amounts of carotenoids, commonly used in the food industry as a colourant for sauces, soups, or meat-based meals. It is also used in cosmetic products such as liquid emulsions and creams (Govindarajan, 1986). The colouration capacity of paprika oleoresin is due to its high content of carotenoids, which represent the pigment pattern of red pepper. This includes seven carotenoids, of which capsanthin, epoxycapsanthin and capsorubin are exclusively synthesised in red pepper (Curl, 1962; Davies et al. 1970). In addition, $\beta$-carotene and $\beta$-cryptoxanthin, both provitamin A carotenoids, and the dihydroxylated xanthophylls zeaxanthin, cucurbitaxanthin $\mathrm{A}$ and violaxanthin are present. Fig. 1 shows the structure of the carotenoids present in the fruit and its products paprika and paprika oleoresin. The xanthophylls are almost completely esterified with fatty acids, saturated fatty acids in the case of capsanthin and capsorubin; mainly unsaturated fatty acids are conjugated to the other xanthophylls (Philip et al. 1971; Camara \& Moneger, 1978; Mínguez-Mosquera \& Hornero-Méndez, 1994).

Carotenoids present in paprika oleoresin may be absorbed from the diet. In this case, not only carotenoids with provitamin A activity are available, but also carotenoids with particular structural features that might exhibit biological properties, including antioxidant and non-antioxidant activities (Britton, 1995; Stahl et al. 2002a). The oxocarotenoids capsanthin and capsorubin exhibit greater antioxidant capacity than other xanthophylls (Pérez-Gálvez \& Mínguez-Mosquera, 2002). This was attributed to structure-related properties, particularly the presence of the keto groups, which, similarly to other oxocarotenoids, improve antioxidant activity by lowering the rate of autoxidation (Terao, 1989; Martin et al. 1999;

\footnotetext{
Abbreviation: AUC, area under the time-response curve.

* Corresponding author: Professor Wilhelm Stahl, fax +49 211811 3029, email wilhelm.stahl@uni-duesseldorf.de
} 

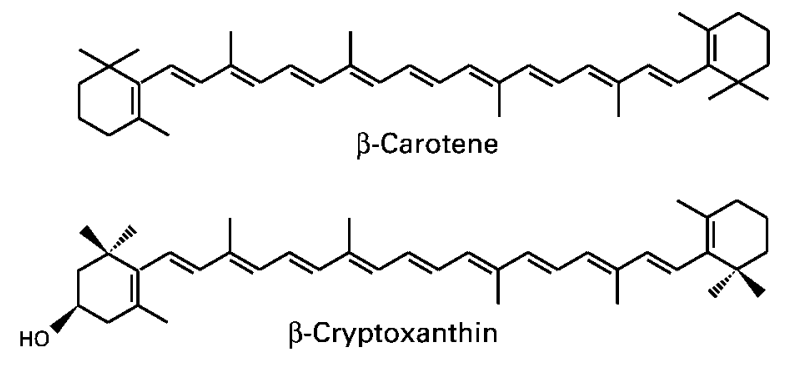<smiles>CC1=C(/C=C/C(C)=C/C=C/C(C)=C/C=C/C=C(C)/C=C/C=C(C)/C=C/C2=C(C)[C@H](O)CC2(C)C)C(C)(C)C[C@H](O)C1</smiles>

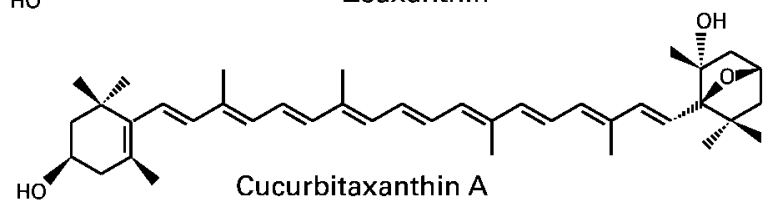

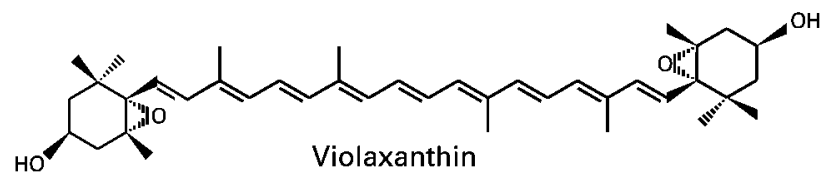<smiles>CC1=C(/C=C/C(C)=C/C=C/C(C)=C/C=C/C=C(C)/C=C/C=C(C)/C=C/C(=O)C2(C)CC(C)CC2(C)C)C(C)(C)CC(O)C1</smiles>

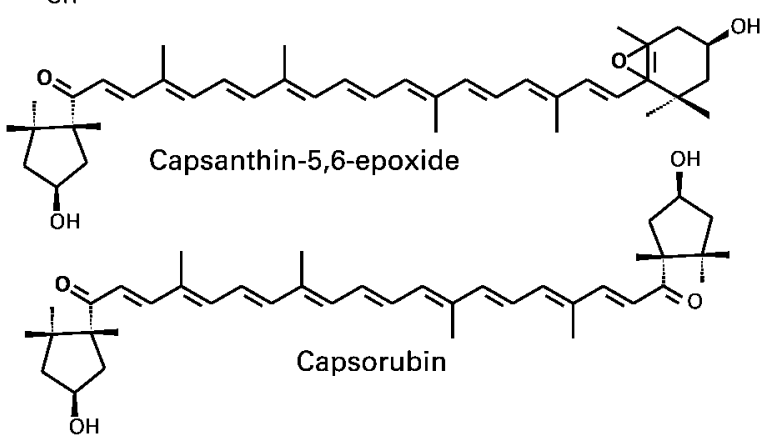

Fig. 1. Structures of the carotenoids present in red pepper (Capsicum annuum L.) and in its processed products, paprika and paprika oleoresins.

Beutner et al. 2001). Paprika oleoresin also contains considerable amounts of zeaxanthin, a carotenoid that together with lutein forms the human macular pigment. The macular carotenoids are suggested to play a role in the protection against macular degeneration, a common eye disease in the elderly (Mares-Perlman et al. 2002).

The processes involved in carotenoid uptake and transport in the human organism are complex and are only partially understood. Absorption is influenced by various factors, including structural features, matrix effects, fibre consumption, availability of additional dietary fat components, the vitamin A status of the organism or food processing (Parker, 1997; van Het Hof et al. 2000; Stahl et al. 2002b). After ingestion, carotenoids are incorporated into micelles formed from lipids and bile acids. The carotenoid-loaded micelles are transferred into intestinal mucosa cells, where part of the carotenoids and retinyl esters are assembled into chylomicrons and transported to the blood via the lymphatic system. The analysis of the carotenoid pattern in the chylomicron fraction of blood plasma at different time points allows investigation of absorption processes.

\section{Subjects and methods}

\section{Materials}

Paprika oleoresin was kindly provided by EVESA (La Línea de la Concepción, Cádiz, Spain). All other chemicals were obtained from Merck (Darmstadt, Germany) with analytical or HPLC grade purity. The raw material is an oil rich in carotenoids with the xanthophylls almost completely esterified with fatty acids (Mínguez-Mosquera \& Hornero-Méndez, 1994). The analysis of the carotenoid concentration was done according to Mínguez-Mosquera \& Hornero-Méndez (1993); $\beta$-apo- 8 -carotenol was used as internal standard. The method for ester cleavage was published previously by Mínguez-Mosquera \& Pérez-Gálvez (1998b). The procedure does not affect the stability of the carotenoids: recovery was about $90 \%$. For ester cleavage, a sample of $25 \mathrm{mg}$ was dissolved in $50 \mathrm{ml}$ diethyl ether and $25 \mathrm{ml} \mathrm{KOH} \mathrm{(100} \mathrm{g/l} \mathrm{methanol)} \mathrm{was}$ added. An appropriate amount of the internal standard was added for subsequent quantification. After complete de-esterification ( $1 \mathrm{~h}$ at room temperature) $200 \mathrm{ml} \mathrm{NaCl}$ ( $100 \mathrm{~g} / \mathrm{l}$ water) was added and the aqueous and organic phases were allowed to separate. The aqueous phase was discarded, and the organic phase was washed several times with $200 \mathrm{ml}$ distilled water until neutral $\mathrm{pH}$. The organic phase, containing the carotenoids, was filtered through a solid bed of anhydrous sodium sulfate, and the filtrate was evaporated to dryness under vacuum. The residue was dissolved in $10 \mathrm{ml}$ acetone (HPLC grade) and stored at $-20^{\circ} \mathrm{C}$ until analysis by HPLC.

\section{Study design}

Nine healthy volunteers (four female and five male, 23-31 years old, non-smokers) took part in the study. They fasted overnight before the start of the study; during the study they consumed a controlled diet with negligible amounts of carotenoids and fat. Oleoresin (1 g) was ingested together with $5 \mathrm{~g}$ oil and white bread. The dose of individual carotenoids ingested is given in detail in Table 1. The study was in accordance with the Helsinki Declaration, updated in Tokyo, Japan in 1975. All subjects gave their informed consent for all procedures. 
Table 1. Carotenoid pattern of paprika oleoresin used in the study ${ }^{\star}$ (Mean values with their standard errors for four analyses)

\begin{tabular}{lccccc}
\hline & \multicolumn{2}{c}{$\begin{array}{c}\text { mg/g of } \\
\text { sample }\end{array}$} & & \multicolumn{2}{c}{$\%$} \\
\cline { 2 - 3 } \cline { 6 - 7 } Carotenoid & Mean & SEM & & Mean & SEM \\
\hline Capsorubin & 2.04 & 0.04 & & 3.27 & 0.04 \\
Violaxanthin & 2.38 & 0.08 & & 3.82 & 0.07 \\
Capsanthin-5,6-epoxide & 1.83 & 0.11 & & 2.93 & 0.11 \\
Capsanthin & 24.6 & 0.44 & & 39.4 & 0.41 \\
9-cis-Capsanthin & 10.4 & 0.29 & & 16.7 & 0.26 \\
Curcurbitaxanthin A & 4.25 & 0.03 & & 6.81 & 0.03 \\
Zeaxanthin & 5.29 & 0.03 & & 8.48 & 0.03 \\
9-cis-Zeaxanthin & 1.11 & 0.02 & & 1.78 & 0.02 \\
B-Cryptoxanthin & 4.24 & 0.06 & & 6.80 & 0.06 \\
$\beta$-Carotene & 6.23 & 0.08 & & 9.99 & 0.07 \\
Total carotenoids & 62.4 & 0.06 & 100 & \\
\hline
\end{tabular}

* Paprika oleoresin was provided by EVESA (La Línea de la Concepción, Cádiz, Spain).

† Since $1 \mathrm{~g}$ paprika oleoresin was ingested as a single dose, these values also represent the doses of individual carotenoids consumed in a single ingestion by each volunteer.

\section{Sample preparation for chylomicrons}

Blood $(10 \mathrm{ml})$ was taken just before $(0 \mathrm{~h})$ and 2, 4, 5, 6, 7, 9 and $12 \mathrm{~h}$ after intake of the paprika oleoresin. Blood samples were centrifuged after clotting $(30 \mathrm{~min}$ in the dark at room temperature) for $10 \mathrm{~min}$ at $2000 \mathrm{~g}$ at $4^{\circ} \mathrm{C}$ to obtain serum. Chylomicrons were prepared according to the method described by Terpstra (1985). Serum (2 ml) was mixed with $\mathrm{KBr}(770 \mathrm{mg})$, sucrose $(50 \mathrm{mg})$ and ethylene glycol $(200 \mu \mathrm{l})$. The mixture was overlaid with $2 \mathrm{ml}$ $\mathrm{KBr}$ solution $(\delta 1.225 \mathrm{~kg} / \mathrm{l}), 4 \mathrm{ml} \mathrm{KBr}(\delta 1.100 \mathrm{~kg} / \mathrm{l})$ and $4 \mathrm{ml}$ distilled water. Chylomicrons were isolated after ultracentrifugation $\left(100000 \mathrm{~g}\right.$ at $20^{\circ} \mathrm{C}$ for $\left.40 \mathrm{~min}\right)$ and stored at $-70^{\circ} \mathrm{C}$ until analysis.

\section{Sample preparation for HPLC}

All the following steps were performed under diminished light. An appropriate amount of the sample $(500 \mu \mathrm{l}$ chylomicron preparation) was mixed with $1 \mathrm{ml}$ buffer (2 $\mathrm{mM}-\mathrm{KH}_{2} \mathrm{PO}_{4}-\mathrm{K}_{2} \mathrm{HPO}_{4}$ and 0.7 mM-EDTA, pH 7.2), $1 \mathrm{ml}$ ethanol and $\beta$-apo- $8^{\prime}$-carotenol as internal standard. The carotenoids were extracted with $6 \mathrm{ml}$ hexane-dichloromethane $(5: 1, \mathrm{v} / \mathrm{v})$. This mixture was vortexed for $1 \mathrm{~min}$, sonicated for $5 \mathrm{~min}$ and vortexed again for $1 \mathrm{~min}$ and finally centrifuged for $10 \mathrm{~min}$ at $2000 \mathrm{~g}$ at $20^{\circ} \mathrm{C}$. A portion of the upper phase $(5 \mathrm{ml})$ was withdrawn and the solvent evaporated under $\mathrm{N}_{2}$. The extract was dissolved in $100 \mu \mathrm{l}$
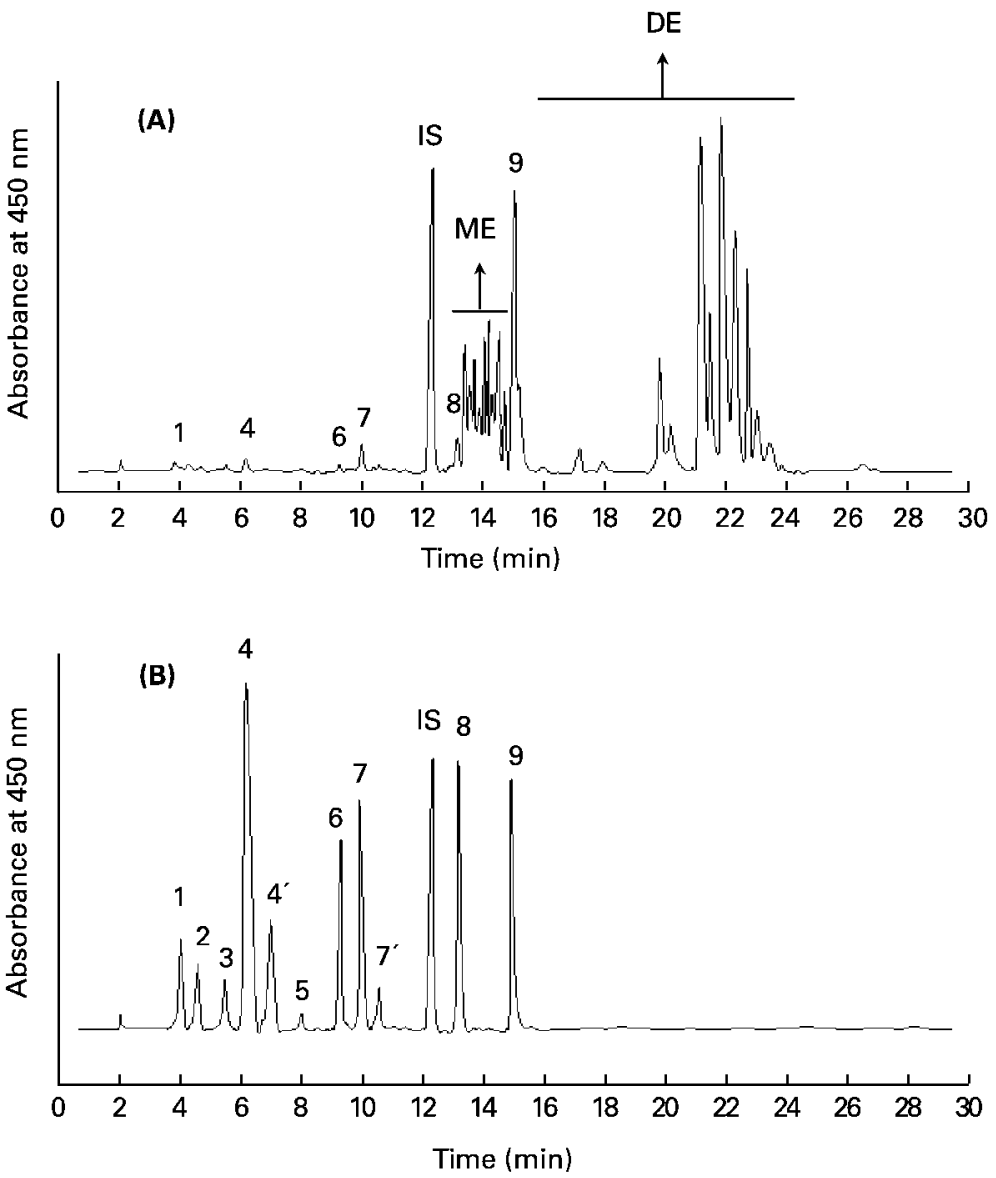

Fig. 2. HPLC chromatograms of paprika oleoresin before $(A)$ and after $(B)$ esters hydrolysis. Peak identification: 1, capsorubin; 2 , violaxanthin; 3, capsanthin-5,6-epoxide; 4, capsanthin; 4', 9-cis-capsanthin; 5, mutatoxanthin; 6, cucurbitaxanthin A; 7, zeaxanthin; 7', 9-cis-zeaxanthin; 8, $\beta$-cryptoxanthin; $9, \beta$-carotene. IS, internal standard; ME, mono-esterified xanthophylls; DE, di-esterified xanthophylls. For details of procedures, see p. 788. 
acetone and stored at $-20^{\circ} \mathrm{C}$ until analysis by HPLC; HPLC analysis was performed within 1 week.

\section{Carotenoid quantification by HPLC}

The chromatographic separation was performed on a reversed-phase column (Spherisorb $\mathrm{C}_{18}$ ODS2, particle size $5 \mu \mathrm{m}, 250 \mathrm{~mm} \times 4 \mathrm{~mm}$; Merck KGaA, Darmstadt, Germany). The eluent comprises a binary gradient at a constant flow of $1.5 \mathrm{ml} / \mathrm{min}$ and detection at $450 \mathrm{~nm}$. The initial composition of the eluent (acetone $-\mathrm{H}_{2} \mathrm{O}(75: 25, \mathrm{v} / \mathrm{v})$ ) is held for $5 \mathrm{~min}$. A linear gradient is then applied for $5 \mathrm{~min}$ to yield a final composition of acetone $-\mathrm{H}_{2} \mathrm{O}$ of 95:5 (v/v). This composition is held for $7 \mathrm{~min}$. Finally the column is washed for $3 \mathrm{~min}$ with acetone. Carotenoids present in the chylomicron fraction were identified by their spectral and chromatographic characteristics. For comparison, purified standards were used, isolated from red pepper (Capsicum annuит L.). For quantification the internal standard method was applied, using $\beta$-apo- $8^{\prime}$-carotenol. Standards isolation, chromatographic separation and carotenoid quantification are described in detail by Mínguez-Mosquera \& Hornero-Méndez (1993).

\section{Statistical analysis}

The area under the time-response curve $\left(\mathrm{AUC}_{0-12 \mathrm{~h}}\right)$ for each carotenoid was calculated using trapezoidal approximation. Values in the text are means with their standard errors. Data were normally distributed (Kolmogorov-Smirnov test) and analysed parametrically. For each carotenoid detected in the chylomicron extracts, mean values at each time point were compared to test for significant differences (Student's $t$ test). Significance was set at $P<0.01$. The statistical analysis was performed with a statistical software package (STATISTICA for Windows, 5.5, 1999; Statsoft, Inc., Tulsa, OK, USA).

\section{Results}

The carotenoid pattern of the paprika oleoresin used in the present study and the amounts of single carotenoids applied are summarized in Table 1. The major carotenoid is capsanthin with about $56 \%$ total carotenoid content in the sample. $\beta$-Carotene and zeaxanthin contribute about $10 \%$ to the total amount, followed by $\beta$-cryptoxanthin and cucurbitaxanthin A with about $7 \%$. Capsorubin is also present but in minor amounts (3\% total carotenoids) as others like violaxanthin or capsanthin-5,6-epoxide. Fig. 2 shows the HPLC traces of the carotenoid pattern in paprika oleoresin before (Fig. 2(A)) and after hydrolysis (Fig. 2(B)). Only small amounts of free (unesterified) xanthophylls are present (retention time 2-10 min, Fig. 2(A)). About $30 \%$ xanthophylls are present as monoesters and about $60 \%$ as diesters/g.

Fig. 3 shows the HPLC chromatograms of carotenoids in chylomicrons obtained from one individual before $(t 0)$
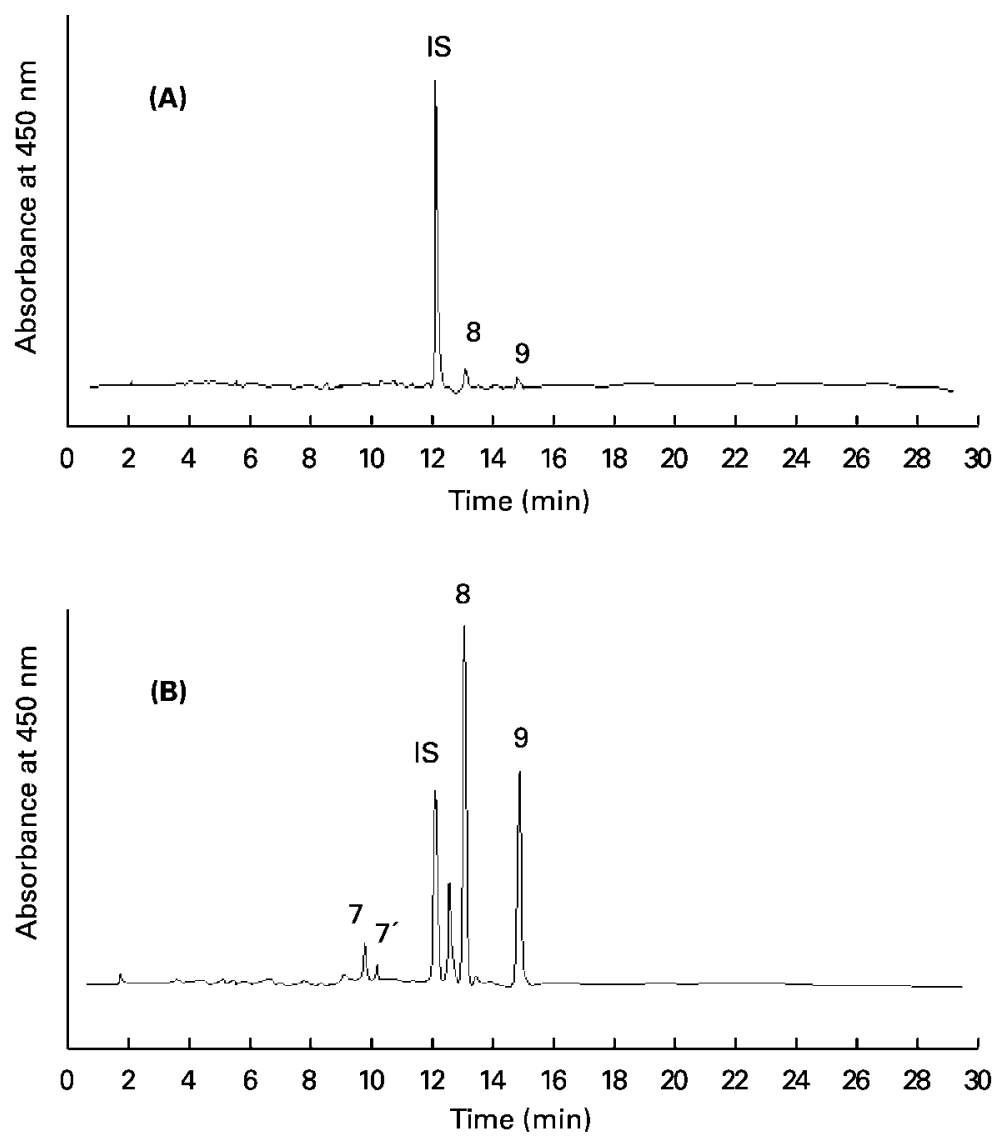

Fig. 3. Chromatograms of chylomicron samples from one subject before $(A)$ and $6 \mathrm{~h}$ after $(\mathrm{B})$ ingestion of paprika oleoresin. Peak identification: 7, zeaxanthin; 7', 9-cis-zeaxanthin; 8, $\beta$-cryptoxanthin; 9, $\beta$-carotene. IS, internal standard. For details of procedures, see p. 788. 
(Fig. 3(A)) and at $t 6 \mathrm{~h}$ (Fig. 3(B)) after ingestion of the paprika oleoresin. From the carotenoids present in the paprika oleoresin (see Fig. 2) only $\beta$-carotene, $\beta$-cryptoxanthin and zeaxanthin were detectable in chylomicrons; the xanthophylls present were unesterified. No significant amounts of other free xanthophylls or their esters were detected in chylomicrons. Very low concentrations of capsanthin below the limit of quantification $(<0.5 \mathrm{nmol} / \mathrm{l})$ were found in two subjects.

The time courses of the mean chylomicron carotenoid levels (nmol/l serum) after ingestion of $1 \mathrm{~g}$ paprika oleoresin are shown in Fig. 4. The concentration of the three carotenoids incorporated into the chylomicrons reached a maximum at about $6 \mathrm{~h}$ after intake: mean serum maximal levels were $(\mathrm{nmol} / \mathrm{l})$ : zeaxanthin 5.73 (SEM 1.14); $\beta$-cryptoxanthin 9.27 (SEM 0.73); $\beta$-carotene 7.53 (SEM 1.12). The $\mathrm{AUC}_{0-12 \mathrm{~h}}$ were $(\mathrm{nmol} \cdot \mathrm{h} / \mathrm{l})$ : zeaxanthin 32.3 (SEM 2.3); $\beta$-cryptoxanthin 56.0 (SEM 5.5); $\beta$-carotene 54.5 (SEM 5.8). Zeaxanthin exhibited the lowest $\mathrm{AUC}_{0-12 \mathrm{~h}}$ value among the carotenoids detected. The value was significantly lower compared with $\beta$-cryptoxanthin and $\beta$-carotene $(P<0.01)$.

\section{Discussion}

Paprika oleoresin contains the provitamin A carotenoids $\beta$-carotene and $\beta$-cryptoxanthin as well as several other xanthophylls, which are mainly present as mono- or diesters of fatty acids. Some of the xanthophylls, capsanthin and capsorubin, are only found in pepper. Although a relative high dose of capsanthin was ingested, the carotenoid was not detectable in human chylomicrons. In addition, no response was observed for capsorubin, violaxanthin, capsanthin epoxide, and cucurbitaxanthin A.

However, the concentration of $\beta$-carotene, $\beta$-cryptoxanthin and zeaxanthin increased significantly $(P<0 \cdot 01)$ in the chylomicron fraction. Maximum levels of the individual carotenoids in chylomicrons were reached at about $6 \mathrm{~h}$, followed by a decrease close to the starting value within $12 \mathrm{~h}$. Such time courses of carotenoids in the chylomicron fraction are typical after ingestion of a supplement or a carotenoid-rich meal (Gärtner et al. 1996; van den Berg H \& van Vliet T, 1998). Only free $\beta$-cryptoxanthin and zeaxanthin were detected in the lipoprotein fraction, although those xanthophylls were mainly esterified in the oleoresin. Apparently, most of the esters are cleaved in the gut or before incorporation into the chylomicrons, an observation that has been described previously (Wingerath et al. 1995). The levels of carotenyl esters in human plasma and tissues are very low even after ingestion of high amounts in the diet (Granado et al. 1998).

There are several factors which influence the uptake of carotenoids from the gut, but it is yet unknown why some of the carotenoids from the paprika oleoresin do not appear in the chylomicron fraction. Although epoxides of $\beta$-carotene have been described in human plasma (Barua, 1999), the epoxide-containing compounds violaxanthin and capsanthin-5,6-epoxide were not present in the chylomicron extracts. They might be chemically degraded under acidic conditions in the stomach or
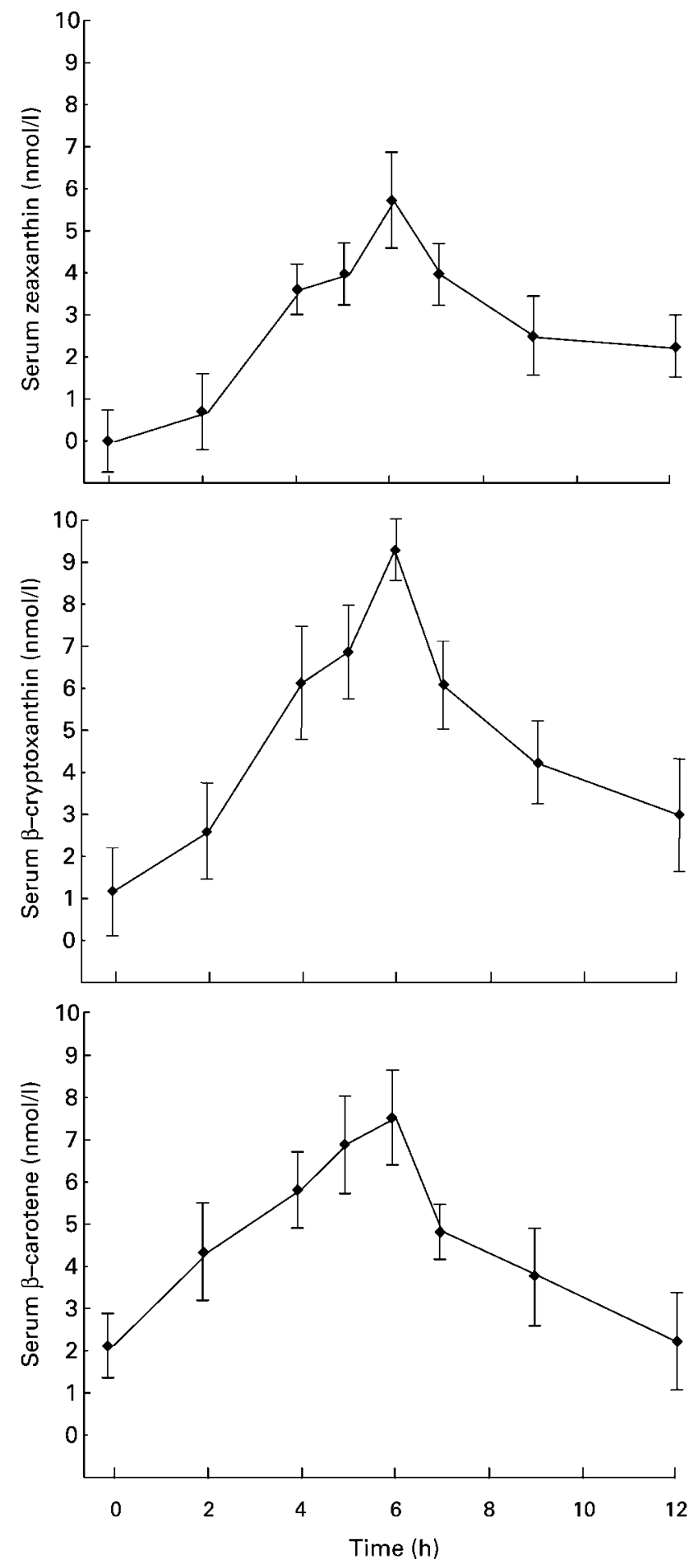

Fig. 4. Time course of the carotenoids present in chylomicrons after ingestion of paprika oleoresin. For details of subjects and procedures, see p. 788. Values are means with their standard errors shown by vertical bars for nine subjects.

enzymatically modified in the gut mucosa cell (Eugster, 1995). However, we did not detect any signals in the HPLC at retention times earlier than capsorubin, as was expected from polar metabolites. King et al. (1997) identified twenty-two structurally different carotenoids (not including cis-trans isomers) in human plasma and 
breast-milk. Among them, there were no epoxide-containing carotenoids like violaxanthin, which occurs in several dietary products but is known to be degraded under acidic conditions. Thus, chemical instability is a reasonable explanation for the lack of carotenoid epoxides in the chylomicrons.

However, we found that cucurbitaxanthin A, capsorubin and capsanthin are relatively stable compounds even at low pH (A Pérez-Gálvez and W Stahl, unpublished results). Therefore, reasons other than chemical instability during the absorption process must be responsible for the poor availability of these carotenoids. It might be that they are not incorporated into mixed micelles or are rapidly metabolized by specific enzymes in the mucosa cell. As xanthophylls were ingested in their esterified form, it is possible that lipases do not cleave esters of oxocarotenoids like capsanthin; this has been recently suggested based on in vitro experiments (Breithaupt et al. 2002). However, an increase of capsanthin in human plasma after ingestion of paprika juice was observed in a previous study (Oshima et al. 1997). The inconsistent results might be due to matrix effects. In agreement with our present results, the authors did not detect the epoxide-containing carotenoids or capsorubin and cucurbitaxanthin A before or after supplementation.

It has been shown that there are differences in the availability of carotenoids depending on the their polarity. Xanthophylls lutein and zeaxanthin are preferentially incorporated into chylomicrons as compared with $\beta$-carotene (Gärtner et al. 1996). From the present study it can be concluded that paprika oleoresin, and probably red pepper, are suitable sources for the provitamin A carotenoids $\beta$-carotene and $\beta$-cryptoxanthin, and the macular carotenoid zeaxanthin.

\section{Acknowledgements}

A. P.-G. is supported by a fellowship from the Postdoctoral Fellowship Program (MEC, Spanish Government). H. S. is a Fellow of the National Foundation of Cancer Research, Bethesda, MD, USA.

\section{References}

Barua AB (1999) Intestinal absorption of epoxy-beta-carotenes by humans. Biochemical Journal 339, 359-362.

Beutner S, Bloedom B, Frixel S, Hernandez-Blanco I, Hoffmann T, Martin HD, Mayer B, Noack P, Ruck C, Schmidt M, Schulke I, Sell S, Ernst H, Haremza S, Seybold G, Sies H, Stahl W \& Walsh R (2001) Quantitative assessment of antioxidant properties of natural colorants and phytochemicals: carotenoids, flavonoids, phenols and indigoids. The role of $\beta$-carotene in antioxidant functions. Journal of the Science of Food and Agriculture 81, 559-568.

Breithaupt DE, Bamedi A \& Wirt U (2002) Carotenol fatty acid esters: easy substrates for digestive enzymes? Comparative Biochemistry and Physiology B 132, 721-728.

Britton G (1995) Structure and properties of carotenoids in relation to function. FASEB Journal 9, 1551-1558.

Camara B \& Moneger R (1978) Free and esterified carotenoids in green and red fruits of Capsicum annuum. Phytochemistry 17, 91-93.

Curl AL (1962) The carotenoids of red bell pepper. Journal of Agricultural and Food Chemistry 10, 522-524.

Davies BH, Matthews S \& Kirk JTO (1970) The nature and biosynthesis of the carotenoids of different color varieties of Capsicum annuum. Phytochemistry 9, 797-805.

Eugster CH (1995) Chemical derivatization: microscale tests for the presence of common functional groups in carotenoids. In Carotenoids: Vol. 1A, Isolation and Analysis, pp. 76-77 [G Britton, S Liaaen-Jensen and H Pfander, editors]. Basel: Birkhäuser-Verlag.

Gärtner C, Stahl W \& Sies H (1996) Preferential increase in chylomicron levels of the xanthophylls lutein and zeaxanthin compared to $\beta$-carotene in the human. International Journal of Vitamin and Nutrition Research 66, 119-125.

Govindarajan VS (1986) Capsicum - Production, technology, chemistry, and quality - part II. Processed products, standards, world production and trade. Critical Reviews in Food Science and Nutrition 23, 207-288.

Granado F, Olmedilla B, Gil-Martinez E \& Blanco I (1998) Lutein ester in serum after lutein supplementation in human subjects. British Journal of Nutrition 80, 445-449.

King TJ, Khachik F, Bortkiewicz H, Fukushima LH, Morioka S \& Bertram JS (1997) Metabolites of dietary carotenoids as potential cancer preventives agents. Pure and Applied Chemistry 69, 2135-2140.

Mares-Perlman JA, Millen AE, Ficek TL \& Hankinson SE (2002) The body evidence to support a protective role for lutein and zeaxanthin in delaying chronic disease. Overview. Journal of Nutrition 132, 518S-524S.

Martin HD, Jager C, Ruck C, Schmidt M, Walsh R \& Paust J (1999) Anti- and prooxidant properties of carotenoids. Journal für Praktische Chemie 341, 302-308.

Mínguez-Mosquera MI \& Hornero-Méndez D (1993) Separation and quantification of the carotenoid pigments in red peppers (Capsicum annuum L.), paprika, and oleoresin by reversedphase HPLC. Journal of Agricultural and Food Chemistry 41, 1616-1620.

Mínguez-Mosquera MI \& Hornero-Méndez D (1994) Changes in carotenoid esterification during the fruit ripening of Capsicum annuum Cv. Bola. Journal of Agricultural and Food Chemistry 42, 640-644.

Mínguez-Mosquera MI \& Pérez-Gálvez A (1998a) Color quality in paprika oleoresins. Journal of Agricultural and Food Chemistry 46, 5124-5127.

Mínguez-Mosquera MI \& Pérez-Gálvez A (1998b) Study of lability and kinetics of the main carotenoid pigments in the de-esterification reaction. Journal of Agricultural and Food Chemistry 46, 566-569.

Oshima S, Ojima F, Sakamoto H, Ishiguro Y \& Terao J (1997) Accumulation and clearance of capsanthin in blood plasma after the ingestion of paprika juice in men. Journal of Nutrition 127, 1475-1479.

Parker RS (1997) Bioavailability of carotenoids. European Journal of Clinical Nutrition 51, S86-S90.

Pérez-Gálvez A \& Mínguez-Mosquera MI (2002) Degradation of non-esterified and esterified xanthophylls by free radicals. Biochimica et Biophysica Acta 1569, 31-34.

Philip T, Nawar WW \& Francis FJ (1971) The nature of the acids and capsanthin esters in paprika. Journal of Food Science 36, 98-102.

Stahl W, Ale-Agha N \& Polidori MC (2002a) Non-antioxidant properties of carotenoids. Biological Chemistry 383, $553-558$

Stahl W, van den Berg H, Arthur J, Bast A, Dainty J, Faulks RM, Gärtner C, Haenen G, Hollman P, Holst B, Kelly FJ, 
Polidori MC, Rice-Evans C, Southon S, van Vliet T, Viña-Ribes J, Williamson G \& Astley SB (2002b) Bioavailability and metabolism. Molecular Aspects of Medicine 23, 39-100.

Terao J (1989) Antioxidant activity of $\beta$-carotene-related carotenoids in solutions. Lipids 24, 659-661.

Terpstra AHM (1985) Isolation of serum chylomicrons prior to density gradient ultracentrifugation of other serum lipoprotein classes. Analytical Biochemistry 150, 221-227.

van den Berg H \& van Vliet T (1998) Effect of simultaneous, single oral doses of $\beta$-carotene with lutein or lycopene on the $\beta$-carotene and retinyl ester responses in the triacylglycerolrich lipoprotein fraction of men. American Journal of Clinical Nutrition 68, 82-89.

van Het Hof KH, West CE, Weststrate JA \& Hautvast JG (2000) Dietary factors that affect the bioavailability of carotenoids. Journal of Nutrition 130, 503-506.

Wingerath T, Stahl W \& Sies H (1995) $\beta$-Cryptoxanthin selectively increases in human chylomicrons upon ingestion of tangerine concentrate rich in $\beta$-cryptoxanthin esters. Archives of Biochemistry and Biophysics 324, 385-390. 